ANNUAL PROGRESS REPORT: YEAR 3

DOE Environmental Management Science Program

Period covered: June 1, 2003 to May 31, 2004

\title{
NOVEL FISSION PRODUCT SEPARATION BASED ON \\ ROOM-TEMPERATURE IONIC LIQUIDS
}

\author{
University of Mississippi Component \\ DOE Grant DE-FC07-01ER63286 \\ Principal Investigator: \\ Charles L. Hussey \\ Department of Chemistry and Biochemistry \\ The University of Mississippi \\ P.O. Box 1848 \\ University, MS 38677-1848
}




\section{Research Objectives:}

The DoE/NE underground storage tanks at Hanford, SRS, and INEEL contain liquid wastes with high concentrations of radioactive species, mainly ${ }^{137} \mathrm{Cs}$ and ${ }^{90} \mathrm{Sr}$. Because the other components of the liquid waste are mainly sodium nitrate and sodium hydroxide, most of this tank waste can be treated inexpensively as low-level waste if ${ }^{137} \mathrm{Cs}$ and ${ }^{90} \mathrm{Sr}$ can be selectively removed. Many ionophores (crown ether and calixarene compounds) have been synthesized for the purpose of selectively extracting $\mathrm{Cs}^{+}$and $\mathrm{Sr}^{2+}$ from an aqueous phase into an immiscible organic phase. Recent studies conducted at $\mathrm{ORNL}^{1,2}$ reveal that hydrophobic ionic liquids might be better solvents for extracting metal ions from aqueous solutions with these ionophores than conventional immiscible organic solvents, such as benzene, toluene, and dichloromethane, because both $\mathrm{Cs}^{+}$and $\mathrm{Sr}^{2+}$ exhibit larger distribution coefficients in the ionic liquids. In addition, the vapor pressures of these ionic liquids are insignificant. Thus, there is little or no vaporization loss of these solvents. Most of the ionic liquids under investigation are relatively nontoxic compared to the hydrocarbon solvents that they replace, classifying them as "green" solvents.

The overall goal of this research project, which includes investigators at ORNL (Drs. Huimin Luo, Sheng Dai, Peter V. Bonnesen, and A.C. Buchanan, III), the University of Alabama (Professor Robin Rogers), and the University of Mississippi (Professor Charles L. Hussey), is to explore the the use of room-temperature ionic liquids as extraction solvents for removing ${ }^{137} \mathrm{Cs}^{+}$ and ${ }^{90} \mathrm{Sr}^{2+}$ from the tank wastes described above. The specific goals of this project are to (a) synthesize new ionic liquids tailored for the selective extraction of ${ }^{137} \mathrm{Cs}$ and ${ }^{90} \mathrm{Sr}$, (b) to select optimum macrocyclic extractants through studies with these fission products, (c) to develop an efficient process for recycling the ionic liquids and ionophores, and (d) to investigate the stabilities of the ionic liquids under extreme conditions, e.g., highly acidic and basic environments and high level radiation fields.

At the University of Mississippi, our primary objective is to evaluate the possibility of recovering $\mathrm{Cs}^{+}$and $\mathrm{Sr}^{2+}$ from the hydrophobic ionic liquid phase by using electrochemical methods after these ions have been extracted from an aqueous phase into the ionic liquid. Calix[4]arenebis(tert-octylbenzo-crown-6) (BOBcalixC6) is the ionophore used for $\mathrm{Cs}^{+}$extraction and dicyclohexano-18-crown-6 (DCH18C6) is used for $\mathrm{Sr}^{2+}$. Because it has been established that $\mathrm{Cs}^{+}$can be electrochemically reduced from some organic solvents into mercury film electrodes, this approach was investigated as a method for recovering $\mathrm{Cs}$ and $\mathrm{Sr}$ from the ionic liquid/ionophore mixtures described above. Most of the exploratory work involving the extraction of $\mathrm{Cs}^{+}$and $\mathrm{Sr}^{2+}$ from aqueous solutions into hydrophobic ionic liquids has been based on dialkylimidazolium cations with anions such as $\mathrm{PF}_{6}^{-}$and $\left(\mathrm{CF}_{3} \mathrm{SO}_{2}\right)_{2} \mathrm{~N}^{-}\left(\mathrm{Tf}_{2} \mathrm{~N}^{-}\right){ }^{1,2}$ Unfortunately, long experience with imidazolium-based ionic liquids in the P.I.'s laboratory has determined that the cathodic electrochemical window of these ionic liquids is insufficient to permit the electrochemical reduction of $\mathrm{Cs}^{+}$and $\mathrm{Sr}^{2+}$ into mercury electrodes. Therefore, an additional aspect of the project being carried out at the University of Mississippi involves the synthesis of ionic liquids that can be used to extract $\mathrm{Cs}^{+}$and $\mathrm{Sr}^{2+}$, but are more resistant to reduction than the imidazolium-based ionic liquids. 


\section{Research Progress and Implications:}

I. Synthesis and properties of the tri-n-butylmethylammonium bis[(trifluoromethyl)sulfonyl]imide $\left(\mathrm{Bu}_{3} \mathrm{MeN}^{+} \mathrm{Tf}_{2} \mathrm{~N}\right)$ ionic liquid. - According to the literature, ${ }^{3,4}$ the tetraalkylammonium-based ionic liquids have electrochemical windows with much more negative cathodic limits than the corresponding dialkylimidazolium salts. In order to achieve the desired low-melting behavior needed to produce a room-temperature ionic liquid, the highly unsymmetrical $\mathrm{Bu}_{3} \mathrm{MeN}^{+}$cation was chosen for study. Although the primary focus of this research is electrochemistry, it is necessary to know if this ionic liquid is suitable for use as an extraction solvent when paired with the appropriate ionophore. Figure 1 shows the concentrations of $\mathrm{Cs}^{+}$and $\mathrm{Sr}^{2+}$ remaining in the aqueous layer after extraction experiments with BOBcalixC6 and dicyclohexano-18-crown-6, respectively. All concentrations were determined with flame emission spectroscopy using standard methods.

\begin{tabular}{|l|}
\hline Ionic liquid + toluene $+\mathrm{BOBcalixC} 6$ \\
\hline Ionic liquid + toluene \\
\hline Toluene $+\mathrm{BOBcalixC} 6$ \\
\hline Toluene \\
\hline Ionic liquid + BOBcalixC6 \\
\hline Ionic liquid \\
\hline Ionic liquid + toluene $+\overline{\mathrm{DCH}} 18 \mathrm{C} 6$ \\
\hline Ionic liquid + toluene \\
\hline Toluene $+\mathrm{DCH} 18 \mathrm{C} 6$ \\
\hline Toluene \\
\hline Ionic liquid $+\mathrm{DCH} 18 \mathrm{C} 6$ \\
\hline Ionic liquid \\
\hline \\
\hline
\end{tabular}

Figure 1. The concentration of $\mathrm{Cs}^{+}$and $\mathrm{Sr}^{2+}$ left in aqueous layer after extraction.

The concentrations of $\mathrm{Cs}^{+}$and $\mathrm{Sr}^{2+}$ in the aqueous layer before extraction were $1.0 \mathrm{mM}$ in each case. The text in each bar of this graph indicates the composition of the solvent used for the particular extraction experiment. This figure reveals that the $\mathrm{Bu}_{3} \mathrm{MeN}^{+} \mathrm{Tf}_{2} \mathrm{~N}^{-}$ionic liquid alone or mixed with a little organic solvent has an extraordinary ability for extracting $\mathrm{Cs}^{+}$and $\mathrm{Sr}^{2+}$ from aqueous solutions when paired with a suitable ionophore. The results for $\mathrm{Cs}^{+}$extraction are particularly noteworthy. 
The electrochemical cathodic limits measured at a platinum electrode in 1-butyl-3methylimidazolium triflate $\left(\mathrm{BuMeIm}{ }^{+} \mathrm{Tf}_{2} \mathrm{~N}^{-}\right)$and $\mathrm{Bu}_{3} \mathrm{MeN}^{+} \mathrm{Tf}_{2} \mathrm{~N}^{-}$are illustrated in Fig. 2. This figure shows that the cathodic limit of the electrochemical window obtained in $\mathrm{Bu}_{3} \mathrm{MeN}^{+} \mathrm{Tf}_{2} \mathrm{~N}^{-}$is $\sim 0.6 \mathrm{~V}$ more negative than that of BuMeIm ${ }^{+} \mathrm{Tf}_{2} \mathrm{~N}^{-}$. This extraordinarily negative electrochemical window makes it possible to electrochemically reduce ionophore-coordinated $\mathrm{Cs}^{+}$and $\mathrm{Sr}^{2+}$ to the respective metal in this ionic liquid at a $\mathrm{Hg}$-film electrode.

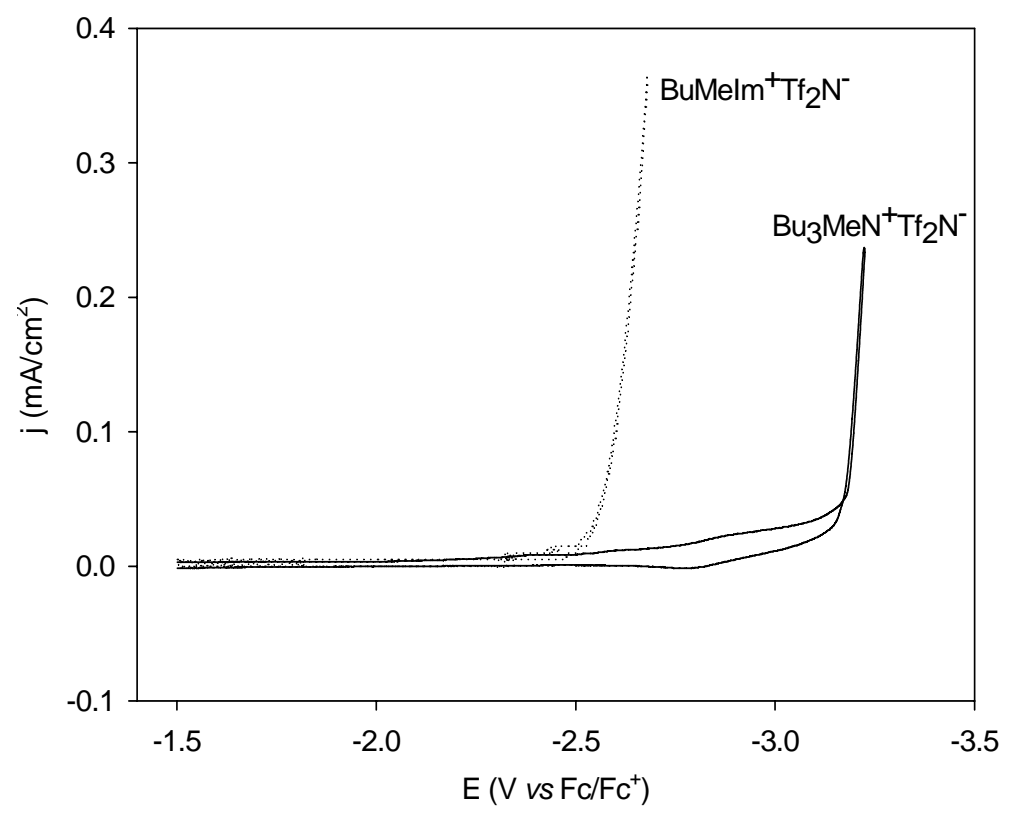

Figure 2. The cathodic electrochemical limits recorded at a $\mathrm{Hg}$ film electrode at $30^{\circ} \mathrm{C}$ in the ionic liquid indicated in the plot.

II. The electrochemical behavior of uncomplexed $\mathrm{Cs}^{+}$and ionophore coordinated $\mathrm{Cs}^{+}$and $\mathrm{Sr}^{2+}$.- Cyclic voltammograms recorded for $\mathrm{Cs}^{+}$at $\mathrm{Hg}$ and $\mathrm{W}$ electrodes are shown in Fig. 3. Waves $\mathrm{c}_{1}$ and $\mathrm{c}_{1}$, represent the deposition of $\mathrm{Cs}$, and $\mathrm{a}_{1}$ and $\mathrm{a}_{1}$, are the corresponding oxidation waves. These results verify that it is possible to reduced $\mathrm{Cs}^{+}$to the metal in this melt; however, the reduction of $\mathrm{Cs}^{+}$at the $\mathrm{W}$ electrode occurs close to the cathodic limit of the ionic liquid. Because of the positive potential shift associated with the free energy change accompanying amalgam formation, $\mathrm{Hg}$ is the electrode of choice. Being a liquid electrode material, the $\mathrm{Cs}$ and $\mathrm{Sr}$ loaded $\mathrm{Hg}$ can be pumped to a separate facility for removal of the Cs and Sr. Although $\mathrm{Cs}^{+}$can be reduced to the metal in this ionic liquid, it is more important to know if ionophore coordinated-Cs ${ }^{+}$and $-\mathrm{Sr}^{2+}$ can also be reduced to the metal because these are the solvated forms of these metal ions that will exist during the treatment of tank waste. Figure 4 indicates that both of 


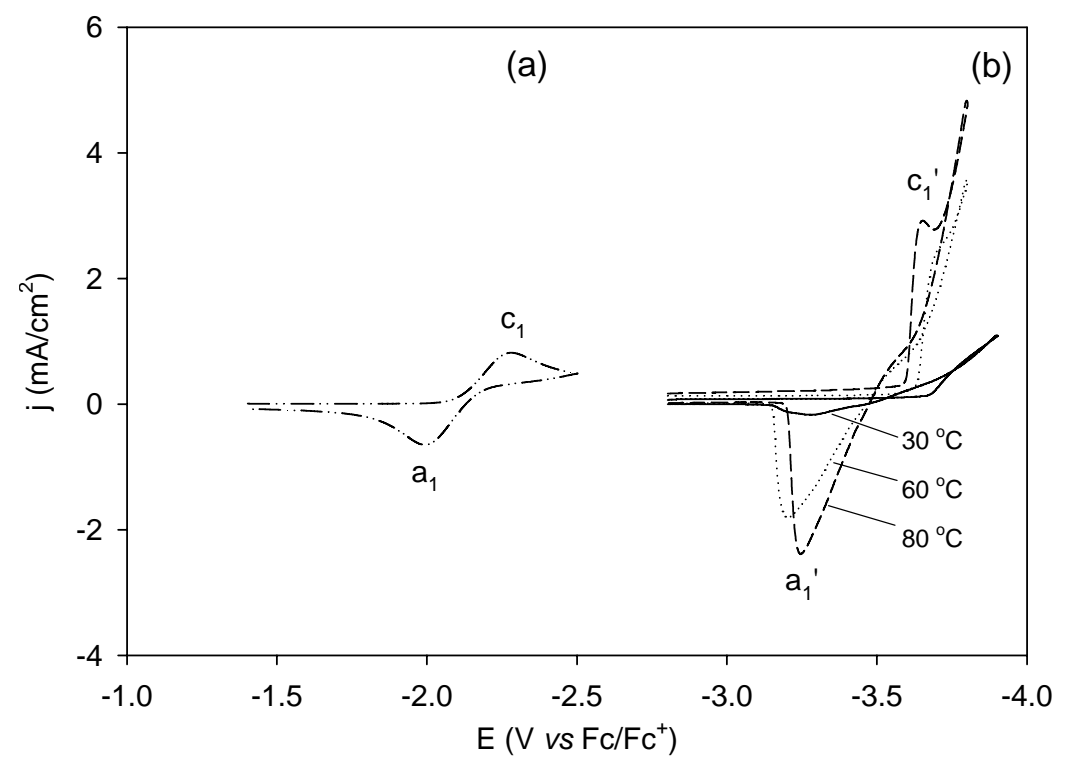

Figure 3. Cyclic voltammograms of $\mathrm{Cs}^{+}$at (a) $\mathrm{Hg}$-drop electrode at $30{ }^{\circ} \mathrm{C}$ and at (b) W electrode at 30,60 , and $80{ }^{\circ} \mathrm{C}$.

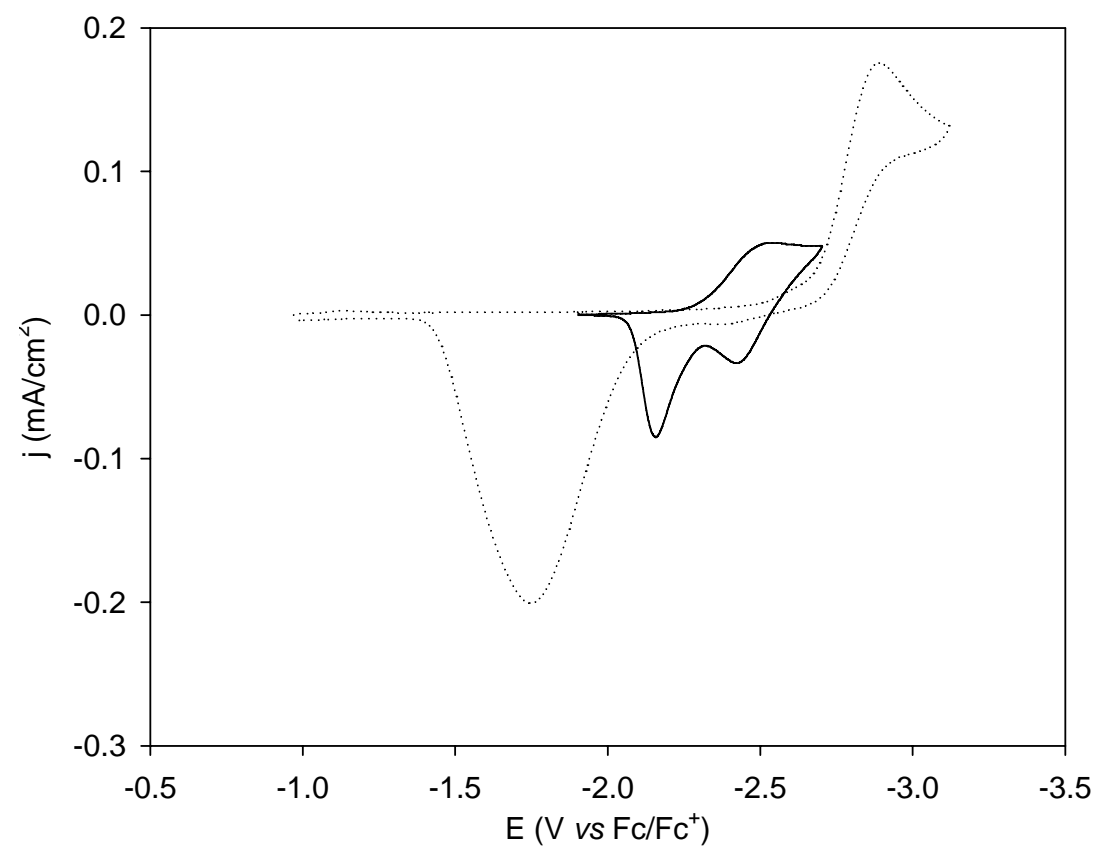

Figure 4. Cyclic voltammograms of $(-) \mathrm{Cs}^{+}$coordinated by BOBcalixC6 and (----) $\mathrm{Sr}^{2+}$ coordinated by DCH18C6 at a $\mathrm{Hg}$ film electrode. 
these coordinated species can be reduced at a $\mathrm{Hg}$ film electrode to produce the corresponding amalgam. Furthermore, the different potentials at which the ionophore coordinated-Cs ${ }^{+}$ and $-\mathrm{Sr}^{2+}$ are reduced suggest that it may be possible to electrochemically separate Cs from $\mathrm{Sr}$ from the ionic liquid solvent. However, we have not yet tested this hypothesis.

III. The electrochemical removal of coordinated-Cs ${ }^{+}$and $-\mathrm{Sr}^{2+}$ and the stability of the resulting amalgam.- Cyclic voltammograms recorded before and after the electrochemical reduction of $\mathrm{Cs}^{+}$and $\mathrm{Sr}^{2+}$ into a mercury pool electrode are presented in Fig. 5. There are no obvious reduction waves in this figure after electrolytic processing was completed. This result suggests that within the detection limit of the cyclic voltammetric technique, all $\mathrm{Cs}$ and $\mathrm{Sr}$ seems to have been removed from the respective ionic liquid/ionophore mixture. Figure 6 shows the coulombic efficiency for the removal of $\mathrm{Cs}$ and $\mathrm{Sr}$ during processing.
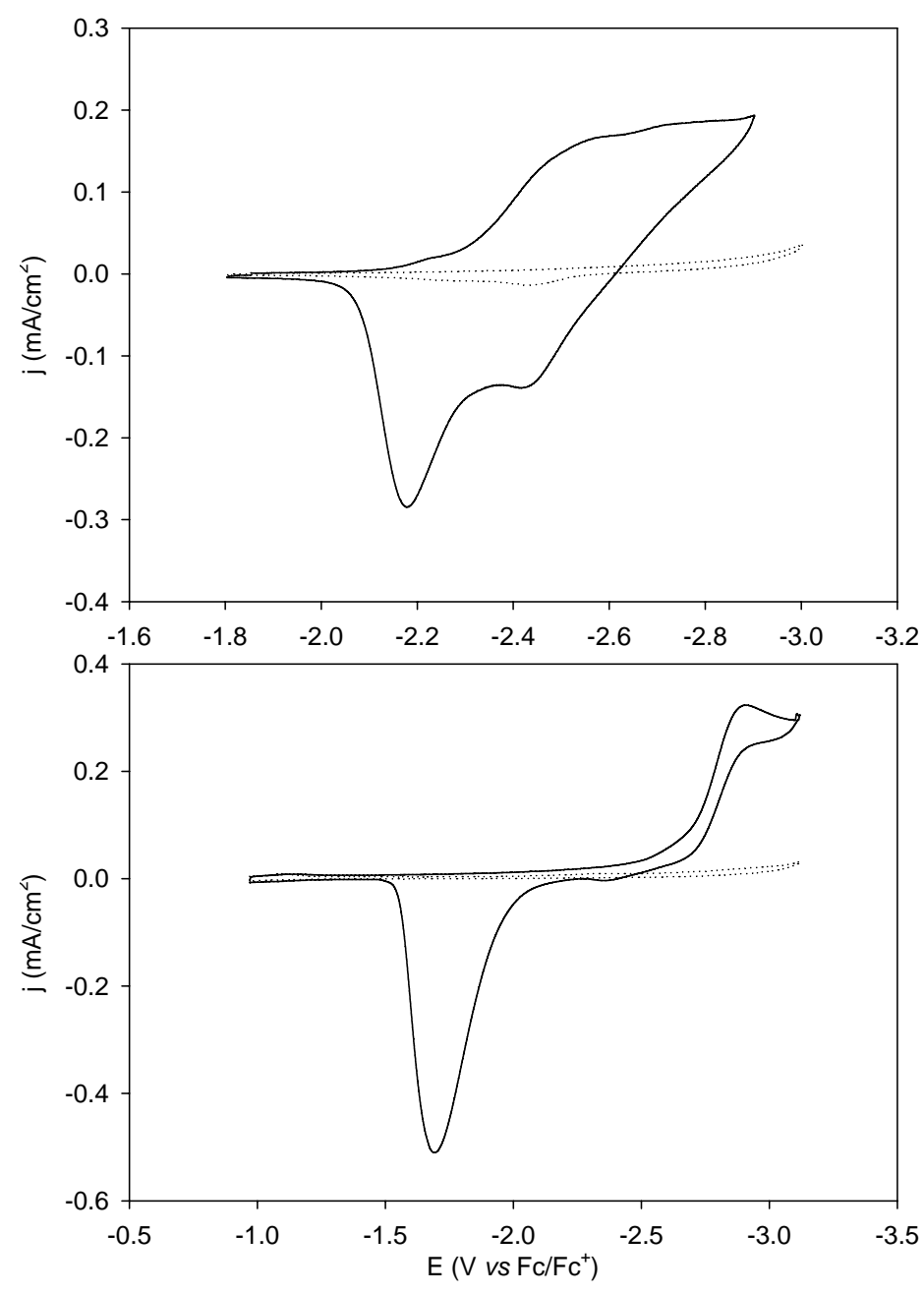

Figure 5. Cyclic voltammograms recorded at a $\mathrm{Hg}$-drop electrode before ( - ) and after (-----) electrolysis at a $\mathrm{Hg}$ film electrode in the ionic liquid containing (a) $\mathrm{Cs}^{+}$ coordinated by BOBcalixC6 and (b) $\mathrm{Sr}^{2+}$ coordinated by DCH18C6. 


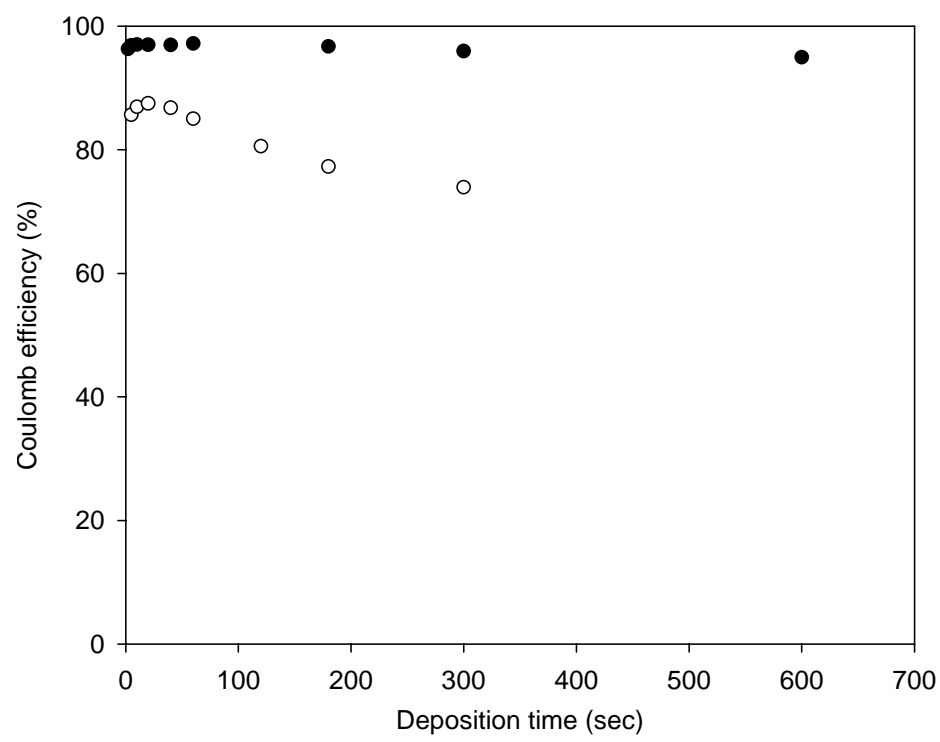

Figure 6. The coulombic efficiency observed at a $\mathrm{Hg}$ film electrode for the removal of $(\bullet) \mathrm{Cs}$ and $(\mathrm{O}) \mathrm{Sr}$.

The coulombic efficiency is defined as the ratio of the stripping charge to the reduction charge during the electrolysis experiment, and it can be viewed as the index of stability of the amalgam produced after reducing the corresponding cations. The columbic efficiency is close to $100 \%$ for $\mathrm{Cs}$, but is somewhat smaller for $\mathrm{Sr}$, In fact, in the latter case, the coulombic efficiency drops to $\sim 70 \% 5 \mathrm{~min}$. after the deposition process has been completed. It is not clear if the $\mathrm{Sr}$ amalgam reacts with impurities in the ionic liquid, such as trace water, or whether it reacts with ionic liquid itself. Furthermore, the products of this reaction have not yet been determined. We are investigating this phenomenon.

$I V$. Work in progress.-We are confident at this point that we can demonstrate the removal of Cs+ and $\mathrm{Sr}^{2+}$ from simulated tank waste by using the $\mathrm{Bu}_{3} \mathrm{MeN}^{+} \mathrm{Tf}_{2} \mathrm{~N}^{-}$ionic liquid with the ionophores, BOBcalixC6 and DCH18C6, respectively, and that it is possible to recover the intact ionic liquid and ionophores by electrochemical removal of the complexed $\mathrm{Cs}^{+}$and $\mathrm{Sr}^{2+}$. However, there is much that we still do not know at this point. Although ionic liquids such as BuMeIm ${ }^{+} \mathrm{PF}_{6}^{-}$, Et$\mathrm{MeIm}^{+} \mathrm{Tf}_{2} \mathrm{~N}^{-}$, and $\mathrm{Bu}_{3} \mathrm{MeN}^{+} \mathrm{Tf}_{2} \mathrm{~N}^{-}$exhibit hydrophobic behavior, they may nevertheless dissolve small amounts of water. The saturated water content of the latter RTIL was estimated by using a gravimetric technique. This technique involved observation of the weight change resulting from the sparging of a weighed portion of the purified ionic liquid with water-saturated $\mathrm{N}_{2}$. These experiments were reversible, i.e., all of the added water could be removed by evacuation at elevated temperatures, restoring the original weight of the ionic liquid before it was saturated with water. The results of these experiments indicated that the saturated water content of $\mathrm{Bu}_{3} \mathrm{MeN}^{+} \mathrm{Tf}_{2} \mathrm{~N}^{-}$was $0.32 \pm 0.01 \%(\mathrm{w} / \mathrm{w})$ at $298 \mathrm{~K}$. This saturated water content is considerably smaller than that of the related EtMeIm ${ }^{+} \mathrm{Tf}_{2} \mathrm{~N}^{-}$ionic liquid, $1.4 \%(\mathrm{w} / \mathrm{w})$ at $288 \mathrm{~K}$ [5]. What we do not know at this point is the water level in the ionic liquid after purification. We know that it is very small. In order to get this information, we are purchasing a coulometric Karl-Fischer ti- 
tration apparatus that can be used to measure the water content of solvents at very low levels. Once this apparatus is in hand, we will conduct an investigation of the effect of the water content on the coulombic efficiency of the electrochemical process for $\mathrm{Cs}^{+}$and $\mathrm{Sr}^{2+}$ removal described above. Another problem that has been identified is the low conductivity and high viscosity of the ionic liquid $\left(\mathrm{Bu}_{3} \mathrm{MeN}^{+} \mathrm{Tf}_{2} \mathrm{~N}^{-}\right)$. The literature suggests that there may be other ionic liquids based on tetraalkylammonium salts with $\mathrm{Tf}_{2} \mathrm{~N}^{-}$anions that possess superior physical properties. Table 1 below compares $\mathrm{Bu}_{3} \mathrm{MeN}^{+} \mathrm{Tf}_{2} \mathrm{~N}^{-}$with $\mathrm{HeEt}_{3} \mathrm{~N}^{+} \mathrm{Tf}_{2} \mathrm{~N}^{-}(\mathrm{He}=$ hexyl). As can be seen in this table, the latter is reported to exhibit lower viscosity and higher conductivity than the former. However, the bulk synthetic preparation of the latter ionic liquid poses certain challenges; strategies to prepare this ionic liquid in bulk quantity are under investigation. Another class of quaternary ammonium that may exhibit the same electrochemical properties to the tetraalkylammonium salts discussed above are those derived from the pyrrolidinium imides, notably $\mathrm{BuMePyN}^{+}$ $\mathrm{Tf}_{2} \mathrm{~N}^{-}$. This salt has physical properties that are superior to $\mathrm{Bu}_{3} \mathrm{MeN}^{+} \mathrm{Tf}_{2} \mathrm{~N}^{-}$(see below), but it is very difficult to prepare and purify. By contrast, $\mathrm{Bu}_{3} \mathrm{MeN}^{+} \mathrm{Tf}_{2} \mathrm{~N}^{-}$is commercially available and requires only modest purification before it can be used. Intensive efforts are underway to identify and prepare some other ionic liquids that have the same very favorable negative potential limit as $\mathrm{Bu}_{3} \mathrm{MeN}^{+} \mathrm{Tf}_{2} \mathrm{~N}^{-}$, but more favorable physical properties.

Given the exceptional stability of alkali metals in the $\mathrm{Bu}_{3} \mathrm{MeN}^{+} \mathrm{Tf}_{2} \mathrm{~N}^{-}$ionic liquid, we have investigated the electrodeposition of $\mathrm{Li}$ at $\mathrm{Al}, \mathrm{Cu}, \mathrm{Pt}$, and $\mathrm{W}$ electrodes from this ionic liquid and mixtures of this liquid with the co-solvent, propylene carbonate (PC). The purpose of this investigation was to assess the utility of this solvent mixture for use as an electrolyte for applications in lithium batteries. In all cases, voltammetry revealed well-defined reduction and oxidation waves for the deposition and stripping of Li from these solid substrates. Cyclic voltammograms illustrating the deposition and stripping of Li are shown below in Fig. 7. An interesting feature of these voltammograms is that the addition of $\mathrm{Li}^{+}$seems to suppress the reduction of the ionic liquid itself. This phenomenon was seen during the reduction of $\mathrm{Cs}^{+}$in $\mathrm{Bu}_{3} \mathrm{MeN}^{+} \mathrm{Tf}_{2} \mathrm{~N}^{-}$, but the effect was much smaller. The deposition and stripping of Li from Al exhibited an efficiency of about $97 \%$ with a low current due to self-discharge. The diffusion coefficient for $\mathrm{Li}^{+}$in the $\mathrm{Bu}_{3} \mathrm{MeN}^{+} \mathrm{Tf}_{2} \mathrm{~N}^{-}$- $\mathrm{PC}$ mixture was quite respectable, averaging about $1 \times 10^{-7}$ $\mathrm{cm}^{2} \mathrm{~s}^{-1}$ at $298 \mathrm{~K}$. We are also investigating the electrochemistry of $\mathrm{Li}^{+}$in this solvent at $\mathrm{Hg}$ electrodes. A manuscript describing our results with Li has been prepared and is undergoing revision. 

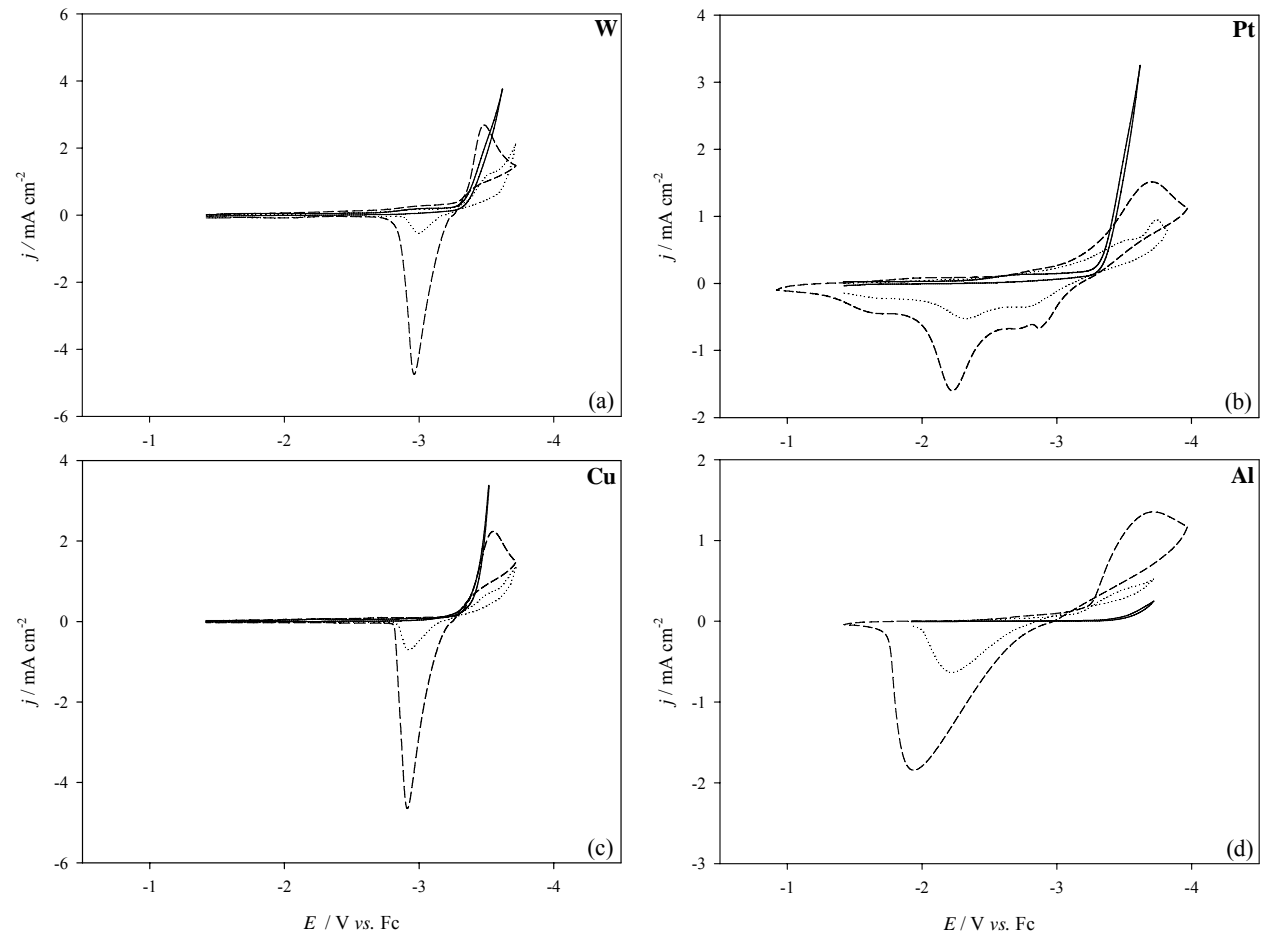

Figure 7. Cyclic voltammograms recorded at tungsten, platinum, copper, and aluminum electrodes: (-) $\mathrm{Bu}_{3} \mathrm{MeN}^{+} \mathrm{Tf}_{2} \mathrm{~N}^{-},(\cdots \cdots \cdot) \mathrm{Bu}_{3} \mathrm{MeN}^{+} \mathrm{Tf}_{2} \mathrm{~N}^{-}+\mathrm{Li}^{+}$, and (----) $\mathrm{Bu}_{3} \mathrm{MeN}^{+} \mathrm{Tf}_{2} \mathrm{~N}^{-}+$ $10 \%(\mathrm{w} / \mathrm{w})$ propylene carbonate $+\mathrm{Li}^{+}$. The sweep rates were $50 \mathrm{mV} \mathrm{s}^{-1}$, and the temperature was at $303 \mathrm{~K}$. 
Table 1. Physical properties of selected room temperature molten salts.

\begin{tabular}{cccccc} 
composition & $\mathrm{mp}(\mathrm{K})$ & $\rho\left(\mathrm{g} \mathrm{cm}^{-3}\right)$ & $\eta(\mathrm{cP})$ & $\kappa\left(\Omega^{-1} \mathrm{~cm}^{-1}\right)$ & Reference \\
\hline $\mathrm{Bu}_{3} \mathrm{MeN}^{+} \mathrm{Tf}_{2} \mathrm{~N}^{-}$ & - & $1.253(303 \mathrm{~K})$ & $386(303 \mathrm{~K})$ & $0.00041(303 \mathrm{~K})$ & This study \\
$\mathrm{HeEt}_{3} \mathrm{~N}^{+} \mathrm{Tf}_{2} \mathrm{~N}^{-}$ & - & $1.27(293 \mathrm{~K})$ & $167(298 \mathrm{~K})$ & $0.00067(298.0 \mathrm{~K})$ & [3] \\
$\mathrm{Bu}_{3} \mathrm{OcN}^{+} \mathrm{Tf}_{2} \mathrm{~N}^{-}$ & - & $1.120(293 \mathrm{~K})$ & $574(298 \mathrm{~K})$ & $0.00013(298.0 \mathrm{~K})$ & [3] \\
$\mathrm{EtMeIm}^{+} \mathrm{BF}_{4}^{-}$ & $\sim 286$ & $1.240(295 \mathrm{~K})$ & $37.7(295 \mathrm{~K})$ & $0.01400(298.0 \mathrm{~K})$ & [6] \\
$\mathrm{EtMeIm}^{+} \mathrm{Tf}_{2} \mathrm{~N}^{-}$ & 270 & $1.520(295 \mathrm{~K})$ & $34.0(293 \mathrm{~K})$ & $0.00880(293.0 \mathrm{~K})$ & [6] \\
$\mathrm{BuMeIm}^{+} \mathrm{BF}_{4}^{-}$ & $\sim 191$ & $1.170(303 \mathrm{~K})$ & $233(303 \mathrm{~K})$ & $0.00173(298.5 \mathrm{~K})$ & [6] \\
$\mathrm{BuMeIm}^{+} \mathrm{PF}_{6}^{-}$ & 212 & $1.370(303 \mathrm{~K})$ & $312(303 \mathrm{~K})$ & $0.00146(298.5 \mathrm{~K})$ & [6]
\end{tabular}




\section{Literature Citations}

1. S. Dai, Y. H. Ju, and C. E. Barnes, J. Chem. Soc. Dalton Trans., 1201 (1999).

2. S. Dai, Y. H. Ju, and H. Luo, in "International George Papatheodorou Symposium”, pp. 254262, Patras Science Park (1999).

3. J. Sun, M. Forsyth, and D. R. MacFarlane, J. Phys. Chem. B, 102, 8858 (1998).

4. K. Xu, M. S. Ding, and T. R. Jow, J. Electrochem. Soc., 148, A267 (2001).

5. P. Bonhôte, A.-P. Dias, M. Armand, N. Papageorgiou, K. Kalyanasundaram, M. Grätzel, Inorg. Chem. 35, 1168 (1996).

6. R. Hagiwara and Y. Ito, J. Fluorine Chem., 105, 221 (2000).

7. A. A. Fannin, Jr., D. A. Floreani, L. A. King, J. S. Landers, B. J. Piersma, D. J. Stech, R. L. Vaughn, J. S. Wilkes, J. L. Williams, J. Phys. Chem., 88, 2641 (1984).

8. D. R. MacFarlane, P. Meakin, J. Sun, N. Amini, and M. Forsyth, J. Phys. Chem. B, 103, 4164 (1999).

\section{Information Access}

Publications:

1. P.-Y. Chen and C. L. Hussey, "Electrodeposition of cesium at mercury electrodes in the tri-1butylmethylammonium bis((trifluoromethyl)sulfonyl)imide room-temperature ionic liquid," Electrochim. Acta, xxxx, 49 (2004) (in press).

2. P.-Y. Chen and C. L. Hussey, "Electrodeposition of coordinated Cs and Sr ions from the tri-1butylmethylammonium bis((trifluoromethyl)sulfonyl)imide room-temperature ionic liquid," Electrochim. Acta, submitted.

3. P.-Y. Chen and C. L. Hussey, "Electrodeposition of lithium from the tri-1-butylmethylammonium bis((trifluoromethyl)sulfonyl)imide room-temperature ionic liquid" (in preparation).

\section{Presentations:}

1. "Electrodeposition of $\mathrm{Cs}$ and $\mathrm{Sr}$ Ions from the Tri-n-butylmethylammonium Triflate Ionic Liquid, 204 ${ }^{\text {th }}$ Meeting of the Electrochemical Society, Orlando, Florida, October 12-16, 2003 (invited). 